\title{
PERANCANGAN GAME BERHITUNG UNTUK ANAK USIA 4-6 TAHUN PADA TK MUSLIMAT NU 09 PENANGGULAN KENDAL
}

\author{
Teguh Setiadi $^{1)}$ Tegar Adi Putra ${ }^{2}$ \\ ${ }^{1,2)}$ Sistem Komputer Sekolah Tinggi Elektronika dan Komputer Pati \\ Correspondence Author: teguh@stekom.ac.id
}

\begin{abstract}
Early-age children live in the world of a play because that's needed a learning medium that is not only interactive but also interesting or more game. Age 4-6 years is a stage of age in an early age range (so-called pre-school age) in which the child is being prepared to enter a formal learning process. Expected in this age range, children have a more focused attitude of learning, not just playing, but began to recognize the learning process behind the game. The result of this research is that Game can be a tool in practicing arithmetic as well as with this game, children who follow numeracy lessons can practice counting by using existing computer facilities. The product of this research produced a medium or a means to introduce computer technology to children from an early age.
\end{abstract}

Keyword: E-Learning, Multimedia, Game Education, Early-age children

\section{INTISARI}

Anak-anak usia dini hidup dalam dunia bermain, karena itulah dibutuhkan suatu media pembelajaran yang tidak hanya interaktif, namun juga menarik atau lebih bersifat permainan. Usia 4-6 tahun adalah suatu tahapan usia dalam rentang usia dini (biasa disebut usia pra-sekolah) dimana anak sedang dipersiapkan untuk memasuki proses belajar yang formal. Diharapkan pada rentang usia ini, anak mempunyai sikap belajar yang lebih terarah, tidak hanya sekedar bermain, namun mulai mengenal proses belajar dibalik permainan tersebut. Hasil dari penelitian ini adalah bahwa Game dapat menjadi alat bantu dalam berlatih berhitung serta dengan adanya game ini, anak-anak yang mengikuti pelajaran berhitung, dapat berlatih berhitung dengan menggunakan fasilitas komputer yang ada. Produk penelitian ini menghasilkan suatu media atau sarana untuk memperkenalkan teknologi komputer kepada anak-anak sejak usia dini.

Kata Kunci : E-Learning, Multimedia, Game Pendidikan, Anak Usia Dini 


\section{PENDAHULUAN}

Sedikit banyak, perkembangan dan kemajuan dalam dunia pendidikan bersangkut paut dengan, bahkan sangat berpengaruh kepada perkembangan teknologi hari ini. Anak-anak usia dini hidup dalam dunia bermain, karena itulah dibutuhkan suatu media pembelajaran yang tidak hanya interaktif, namun juga menarik atau lebih bersifat permainan. Usia 4-6 tahun adalah suatu tahapan usia dalam rentang usia dini (biasa disebut usia pra-sekolah) dimana anak sedang dipersiapkan untuk memasuki proses belajar yang formal. Diharapkan pada rentang usia ini, anak mempunyai sikap belajar yang lebih terarah, tidak hanya sekedar bermain, namun mulai mengenal proses belajar dibalik permainan tersebut. Oleh karena itu, perlunya suatu media bantu belajar dalam bentuk game yang bersifat edukatif.

Berkaitan dengan hal tersebut, penulis melakukan studi kasus pada pada TK Muslimat NU 09 Penanggulan yang berlokasi atau alamatnya di Jalan Kiyai Guru Rt 01 Rw 02 Pananggulan Kecamatan Pegandon Kabupaten Kendal. TK yang memiliki 4 orang pengajar (guru) dan total 68 anak ini, membagi kelas-kelas yang ada ke dalam 3 tingkatan (jenjang), yaitu: pra-Play Group $(2,5$ - 3 tahun) dan Play Group (3 tahun) yang menjadi 1 kelas, kelas TK A ( $3-4$ tahun), serta kelas TK B (4 - 5 tahun). Berdasarkan pembagian kelas tersebut, maka game yang penulis buat adalah untuk anak kelas TK A dan TK B.

Berdasarkan observasi dan survai yang penulis lakukan, penulis mendapati bahwa pelajaran hitung menghitung masih dalam bentuk manual dengan alat peraga misalnya menggunaka karton, kayu dan visual gambar. Hal ini disebabkan oleh pelajaran hitung menghitung di TK Muslimat NU 09 Penanggulan membuat banyak anak-anak belum mengerti dan membingungkan karena hanya bisa dengan alat peraga. Dari keterbatasan alat tersebut dengan mengandalkan alat peraga menjadikan komputer tersebut masih sebatas kegiatan untuk mendata karyawan dan untuk menasukkan data anak. Selain itu, di dalam pelajaran berhitung terdapat beberapa anak yang malas untuk berlatih, yang persentasenya mencapai $25-35 \%$ dalam mengikuti latihannya.

\section{KERANGKA TEORI}

\section{a. Taman Kanak-Kanak}

Anak usia 4-6 tahun merupakan bagian dari anak usia dini yang berada pada rentangan usia lahir sampai 6 tahun. Pada usia ini secara terminologi disebut sebagai anak usia prasekolah. Usia 46 tahun merupakan masa peka bagi anak. Anak mulai sensitif untuk menerima berbagai upaya perkembangan seluruh potensi anak. Masa peka adalah masa terjadinya pematangan fungsi-fungsi fisik dan psikis yang siap merespon stimulasi yang diberikan oleh lingkungan. Masa ini merupakan masa untuk meletakkan dasar pertama dalam mengembangkan kemampuan fisik, kognitif, bahasa, sosial emosional, konsep diri, disiplin, kemandirian, seni, moral, dan nilai-nilai agama. Oleh sebab itu dibutuhkan kondisi dan stimulasi yang sesuai dengan kebutuhan anak agar pertumbuhan dan perkembangan anak tercapai secara optimal.

Tujuan adanya Taman Kanak-Kanak adalah membantu anak didik mengembangkan berbagai potensi baik psikis dan fisik yang meliputi moral dan nilai-nilai agama, sosial emosional, kognitif, bahasa, fisik/motorik, kemandirian dan seni untuk siap memasuki pendidikan dasar. Ruang lingkup kurikulum TK meliputi aspek perkembangan Moral dan Nilai-nilai Agama, Sosial, Emosional dan Kemandirian, Kemampuan Berbahasa, Kognitif (termasuk berhitung), Fisik/motorik dan Seni.

Bermain merupakan pendekatan dalam melaksanakan kegiatan pembelajaran pada anak usia TK (Dewi, 2011). Dengan bermain anak akan merasa senang. Perasaan senang ini akan membuka otak anak untuk belajar. Melalui bermain, anak mendapatkan stimulasi yang memungkinkan terjadinya koneksi sel syaraf, yang jika koneksi tersebut semakin banyak dan kompleks akan menentukan kecerdasan anak (Siantayani, 2011).

\section{b. Game}

Sebuah game adalah suatu aktivitas atau pertandingan yang ditentukan oleh sejumlah peraturan. Orang-orang bermain games untuk rekreasi/hiburan dan untuk mengembangkan kemampuan mental atau fisik. Games memiliki banyak variasi. Ada yang memiliki sejumlah 
pemain dan dapat dimainkan dengan bersaing atau bekerja sama, ada juga yang melibatkan sejumlah besar perlengkapan. Games dapat dikelompokkan dalam beberapa cara, yang meliputi jumlah pemain yang diperlukan, tujuan permainan, gol yang harus dicapai, orang yang memainkannya, atau tempat dimana game itu dimainkan. Cara paling umum dalam mengelompokkan games adalah berdasarkan perlengkapan yang dibutuhkan untuk memainkannya (Schmittberger, 2009).

\section{c. Berhitung}

Berhitung adalah cabang dari matematika. Orang-orang Yunani Kuno menamakan berhitung dengan kata arithmetike, suatu istilah yang diturunkan dari kata arithmos yang berarti "bilangan" dan techne yang berarti "ilmu pengetahuan". Dalam kamus Webster's New Third International Dictionary, kata berhitung dirumuskan sebagai "cabang matematika yang berkenaan dengan sifat dan hubungan bilangan-bilangan nyata dan dengan perhitungan diantaranya, terutama berkenaan dengan penjumlahan, pengurangan, perkalian dan pembagian". Sementara pada kamus Concise Oxford English Dictionary dan American Encyclopedia dengan singkat mengartikan berhitung sebagai "ilmu tentang bilangan" (Poetra, 2010).

\section{METODE PENELITIAN}

\section{a. Kerangka Pemikiran Game}

Kerangka berfikir Game merupakan gambaran tahapan sebuah sistem rancangan game dimana terdapat beberapa data yang merupakan sebuah inputan dari hasil game tersebut. Untuk mengetahui teknik hasil media interaktif maka terdapat beberapa proses dan hasil keluaran berupa data yang di tampilkan dengan beberapa model penyajian. Oleh sebab itu dibutuhkan kerangka berfikir sebagai berikut :

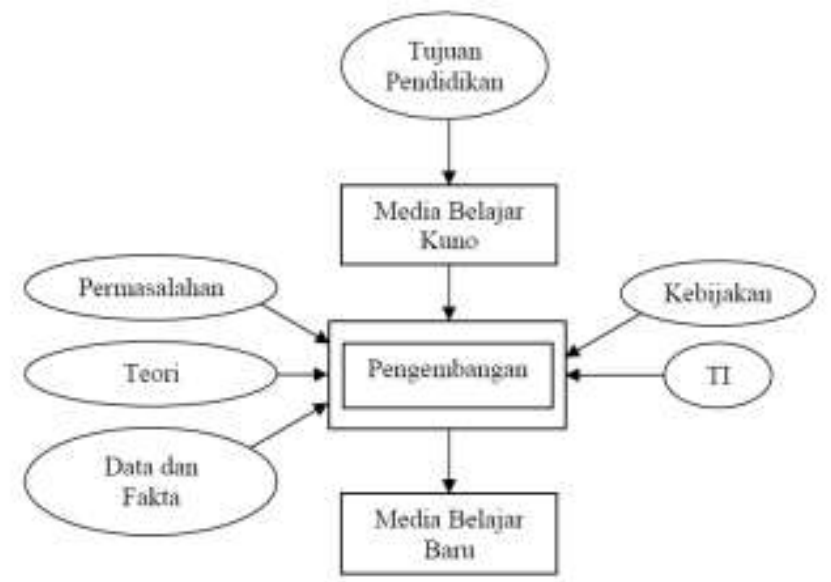

Gambar 1. Kerangka Pemikiran

Penjelasan gambar dari kerangka berfikir adalah sebagai berikut :

1. Berawal dari tujuan pendidikan di Indonesia yang adalah untuk membentuk anak yang berkualitas, maka di dalam proses belajar-mengajar diperlengkapi dengan media belajar.

2. Seiring dengan perkembangan jaman, teknologi pun terus mengalami kemajuan, salah satunya adalah TI (Teknologi Informasi). Adalah dirasa perlu untuk memperkenalkan teknologi kepada anak-anak agar di dalam proses pembentukan anak yang berkualitas, mereka juga menjadi anak yang up to date (mengkuti perkembangan jaman). Karena itulah, dilakukan pengembangan pada media belajar yang sudah ada, yang kemudian disebut sebagai media belajar kuno.

3. Proses pengembangan ini berdasarkan pada permasalahan yang ada, teori-teori, juga data dan fakta serta kebijakan yang berlaku pada obyek penelitian dan melalui sarana Teknologi Informasi. 
4. Melalui proses pengembangan ini, diharapkan dapat menghasilkan suatu media belajar baru yang dapat membantu proses pembentukan anak yang berkualitas dan tidak ketinggalan dengan kemajuan jaman.

\section{b. Desain Game Interaktif}

Spesifikasi produk yang dikembangkan perlu adanya flowchart obyek penelitian agar memberikan kerangka dari game menghitung seperti terlihat pada gambar di bawah ini.

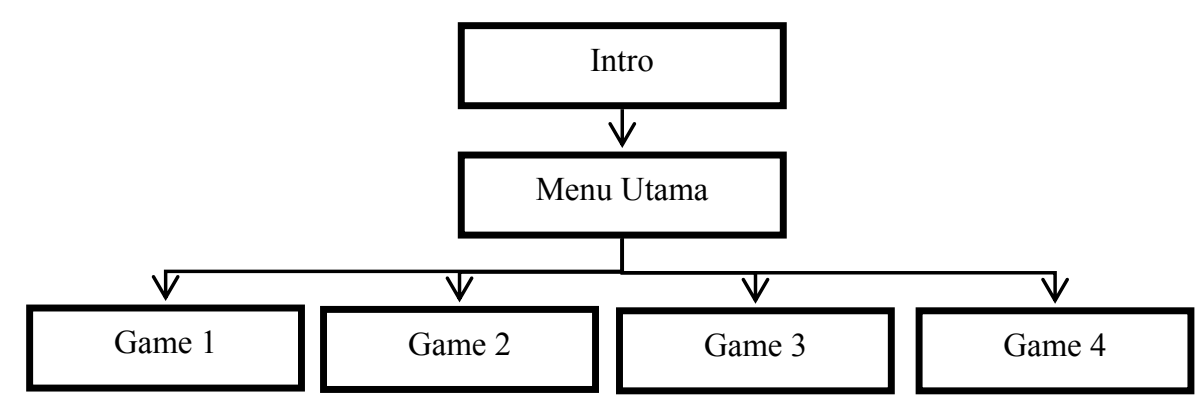

Gambar 2. Flowchart Obyek Pembelajaran interaktif

Untuk menghasilkan desain game interaktif maka dibutuhkan layout, adalah sebagai berikut.

1. Tampilan intro

2. Tampilan Tampilan Flowchart Intro dan Menu Utama

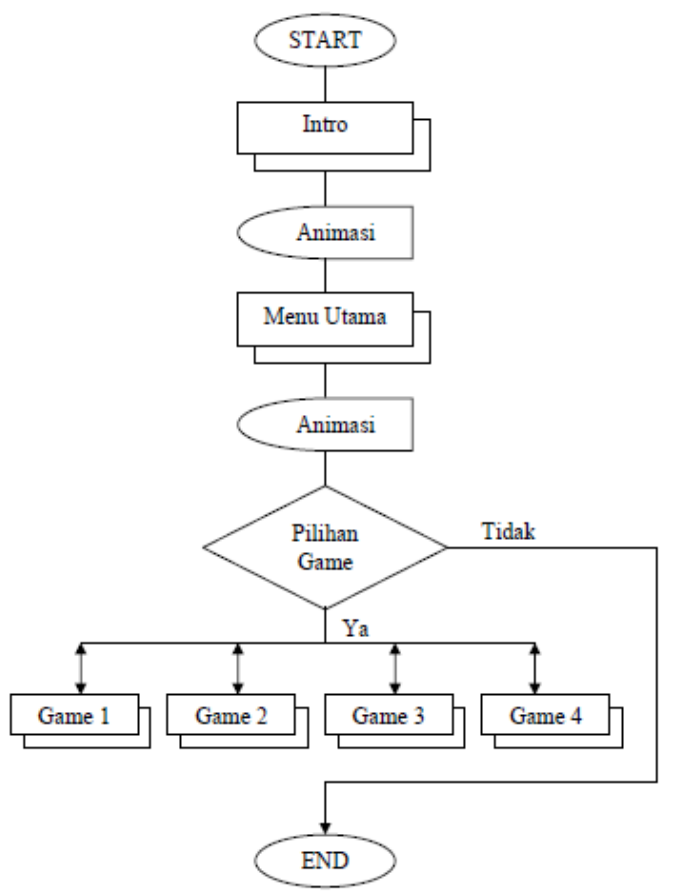

Gambar 3. Tampilan Flowchart Intro dan Menu Utama 
1. Tampilan Flowchart Game 1

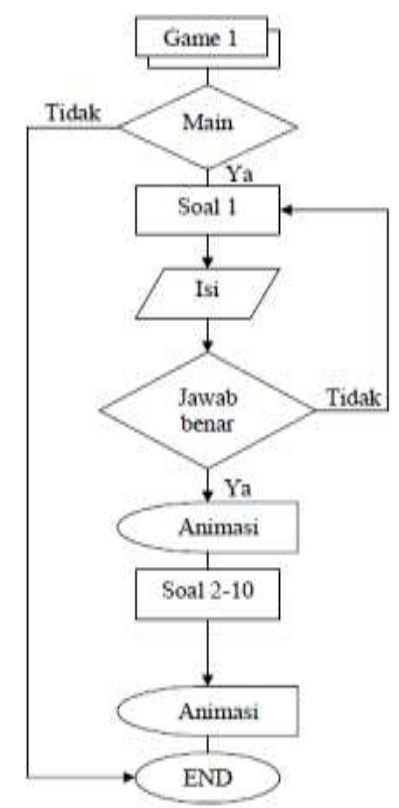

Gambar 4. Flowchart Game 1

3. Tampilan Flowchart Game 2 dan 4

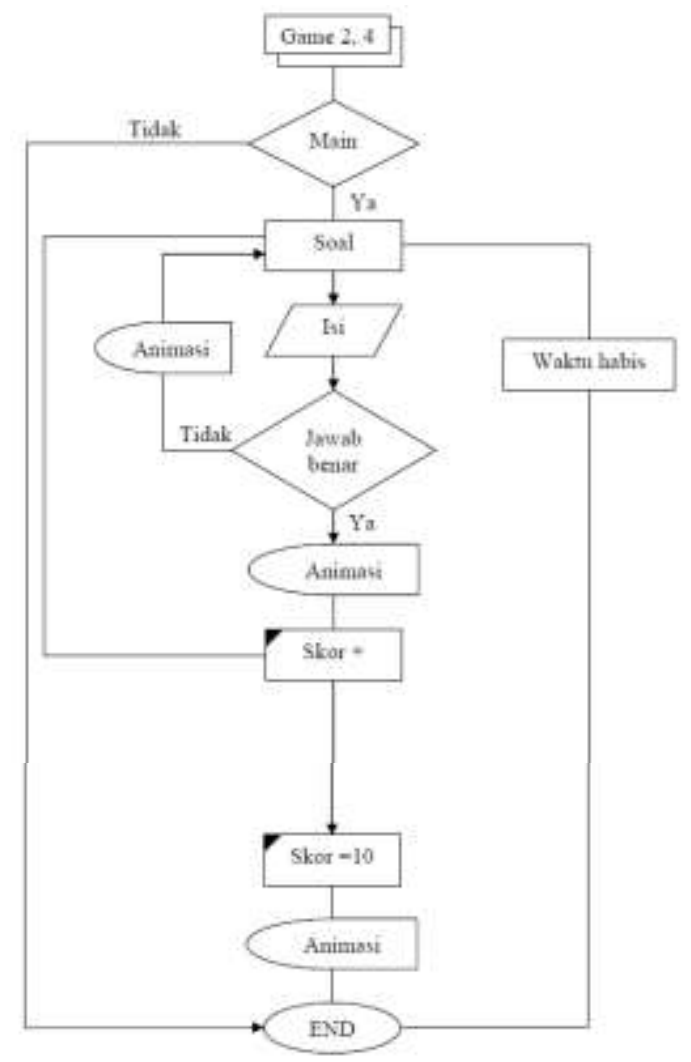

Gambar 5. Tampilan Flowchart Game 2 dan 4 


\section{HASIL DAN PEMBAHASAN}

Hasil penelitian yang telah penulis lakukan telah diterapkan pada TK Muslimat NU 09 Penanggulan dengan mengadakan tes uji coba pada anak baik TK A maupun TK B pada hari Rabu tanggal 21 Maret 2017 pukul 07.00 - 08.30 WIB, Waktu pada kegiatan belajar mengajar. Adapun peralatan yang diperlukan pada saat penerapan hasil penelitian adalah seperangkat komputer dengan mouse, keyboard, speaker, dan CD-ROM atau CD-RW, yang memiliki kebutuhan sistem minimal prosesor Intel Pentium dual Core $450 \mathrm{MHz}$, memori RAM sebesar 2MB, operating system Microsoft Windows 7 dengan browser Microsoft Internet Explorer 5.5, Firefox 1.x, Netscape 7.x, AOL 9, atau Opera 7.11 dan dilengkapi dengan software Flash Player 10.

\section{Desain Tampilan Intro}

Pada hasil akhir tersebut dari perancangan awal sampai selesai maka akan dibahas hasilnya yang akan di uji coba. Lebih lengkapnya untuk melihat tampilan sebagai berikut.

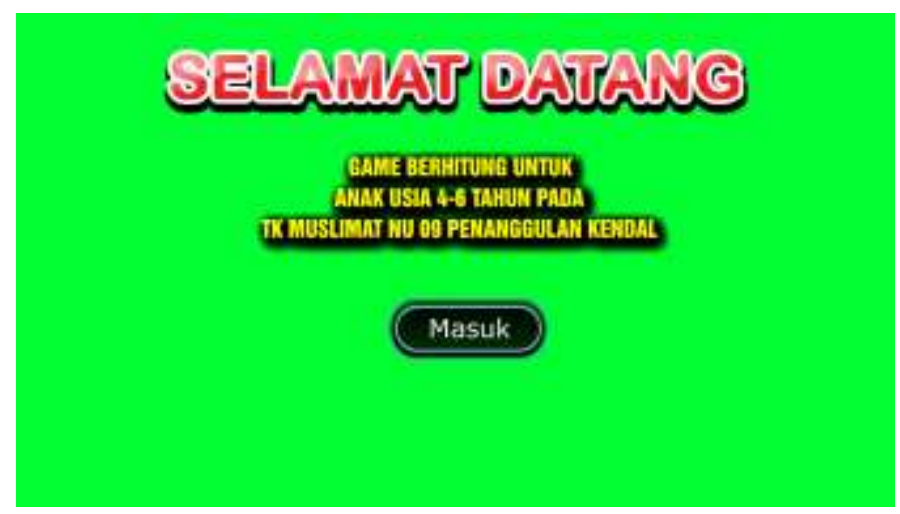

Gambar 6. Tampilan Intro

\section{Desain Tampilan menu 1}

Hasil tampilan dari intro yang berisi tombol menu, jika nantinya di klik maka akan masuk pada menu materi. Lebih jelasnya dapat dilihat pada gambar berikut ini.

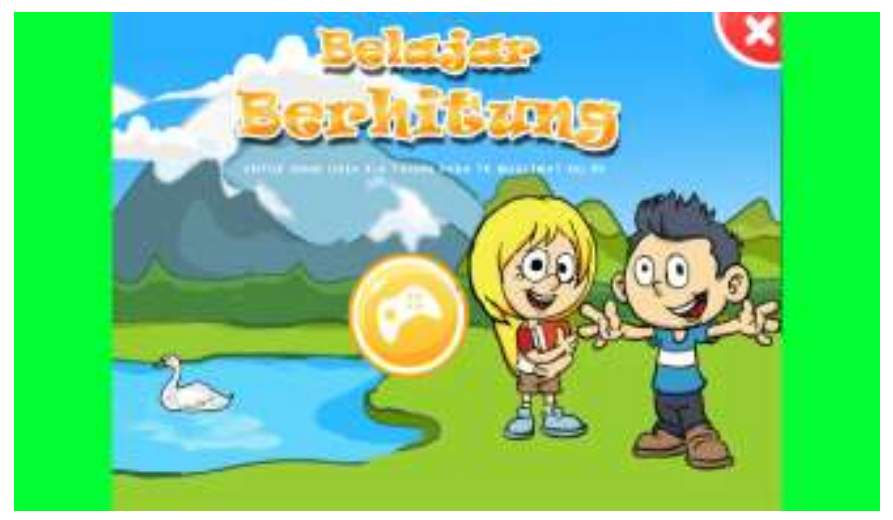

Gambar 7. Tampilan menu 1

\section{Desain Tampilan menu 2 tombol menu}

Dibawah ini menu-menu untuk masuk media game beritung dapat dilihat sebagai berikut ini. 


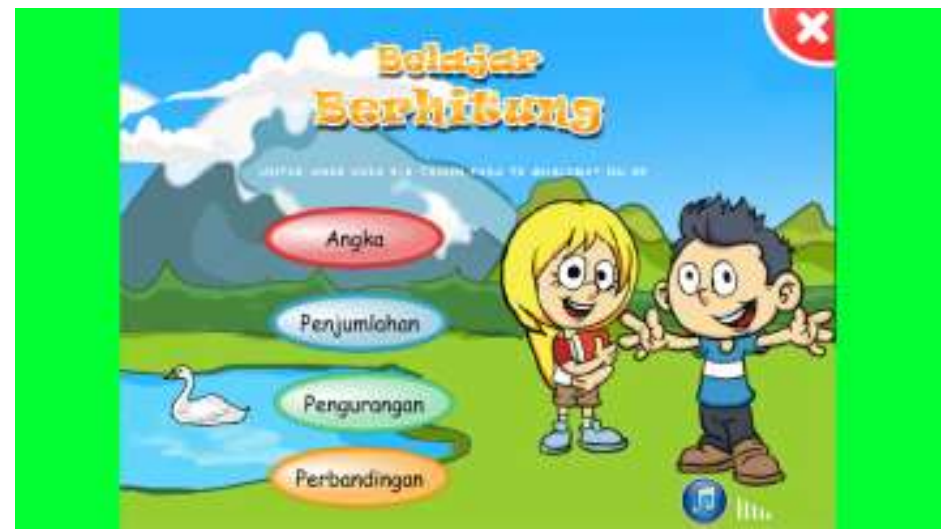

Gambar 8. Tampilan menu 2 tombol menu

\section{Desain Tampilan Soal 1}

Penyelesainnya berikutnya tentang latihan soal yang memberikan penggunaan dalam kutip, untuk mengetahui angka dengan visual gambar. Lebih jelasnya dapat dilihat sebagai berikut ini.

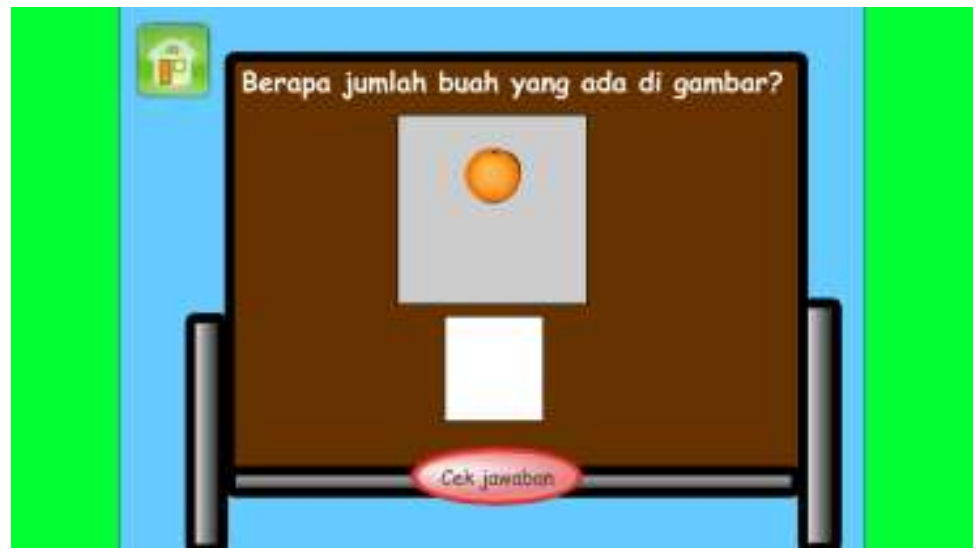

Gambar 9. Tampilan Soal Game 1

\section{Desain Tampilan Soal Penjumlahan}

Tampilan game penjumlahan dengan teknik random yang disertai tentang nilainya. Lebih jelasnya bisa dilihat sebagai berikut.

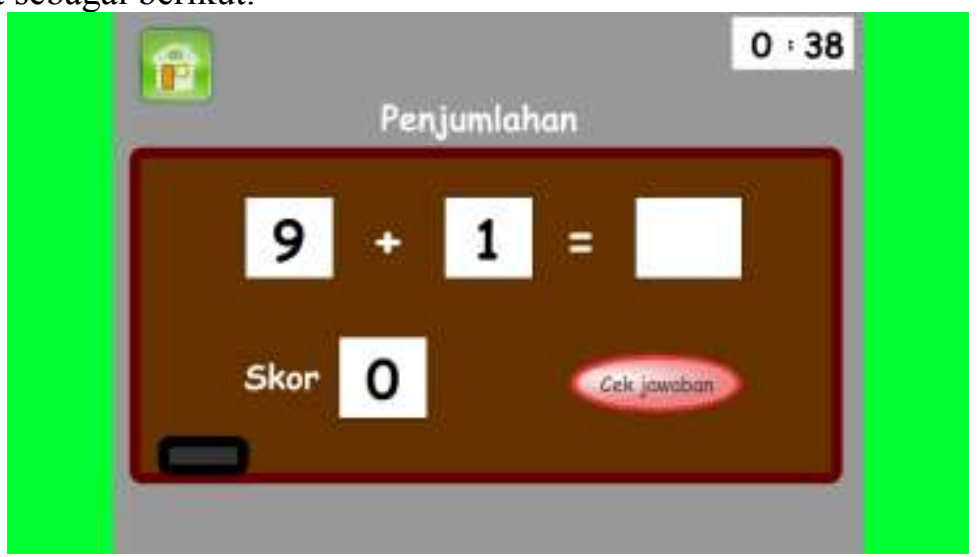

Gambar 10. Tampilan Game 2 Penjumlahan 


\section{Desain Tampilan Soal Pengurangan}

Untuk tampilah pada pengurangan dengan memberikan ketentuan antara angka-angka yang lainnya, ketentuan dengan memberikan teknik penggurangan.

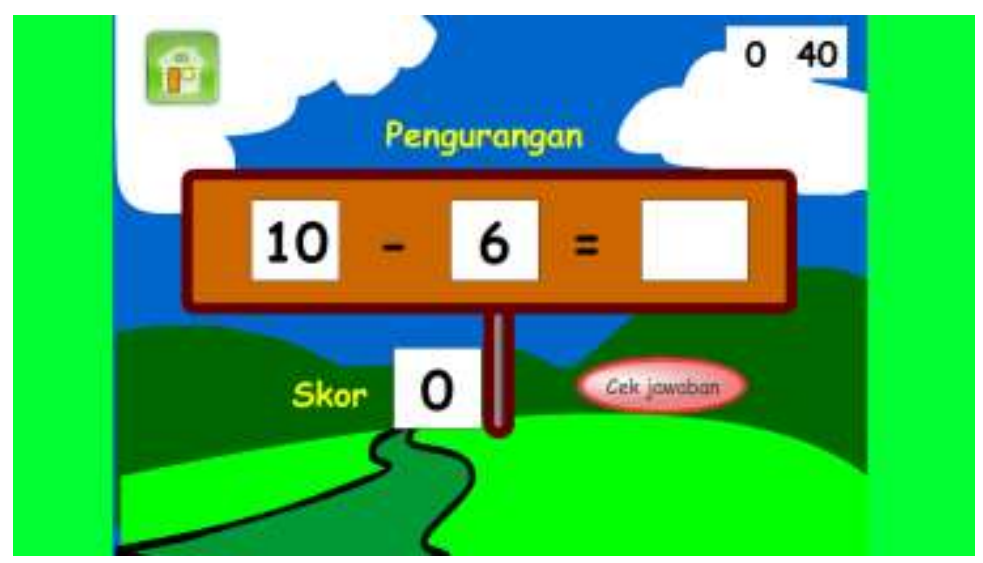

Gambar 11. Tampilan Game 3 Pengurangan

\section{Desain Tampilan Soal Perbandingan}

Pada tampilan terakhir adalah game perbandingan yang digunakan untuk menentukan perbandingan angka - angka dengan teknik random.

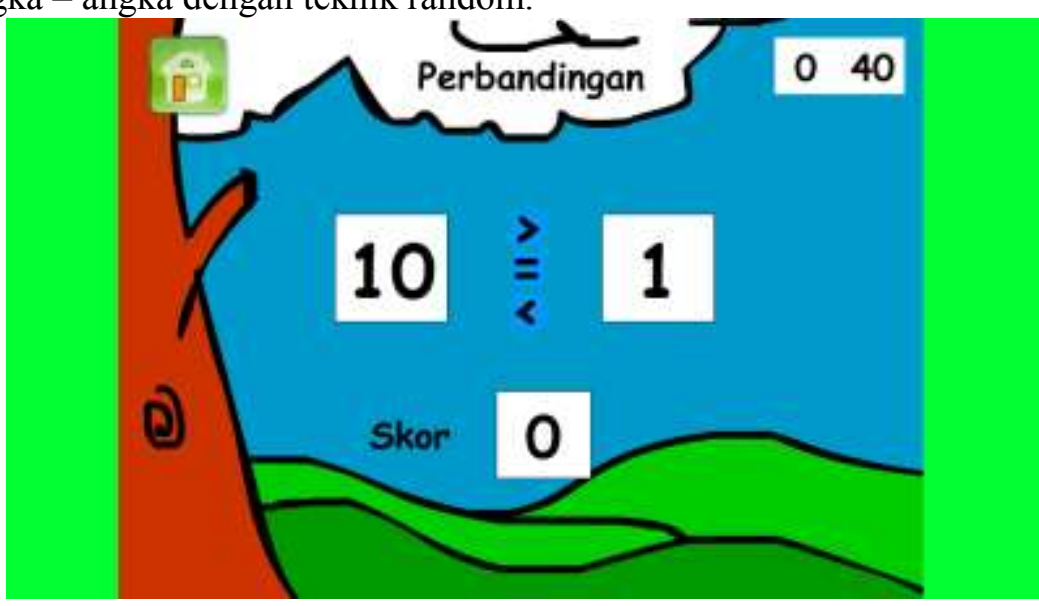

Gambar 12. Tampilan Game 4 Perbandingan

\section{KESIMPULAN}

Berdasar hasil penelitian dari analisis dan survei, maka dapat diambil kesimpulan bahwa :

1. Game ini dapat menjadi suatu alat bantu dalam berlatih berhitung, dikarenakan isi dari game ini yang menuntut anak untuk melakukan proses berhitung agar dapat menyelesaikan game ini dengan baik. Disamping itu game ini dapat diterima dengan baik oleh anak usia 4-6 tahun dari hasil penerapan yang penulis lakukan atas game ini kepada anak-anak TK Muslimat NU 09 Penanggulan Kendal, khususnya anak-anak kelas TK A dan TK B.

2. Dengan adanya game ini, anak-anak yang mengikuti pelajaran berhitung, dapat berlatih berhitung dengan menggunakan fasilitas komputer yang ada.

3. Produk penelitian ini menghasilkan suatu media atau sarana untuk memperkenalkan teknologi komputer kepada anak-anak sejak usia dini. 


\section{DAFTAR PUSTAKA}

Dewi Ani Kumala, 2011. “ Standar Kompetensi Taman Kanak-Kanak dan Raudhatul Athfal “, Jakarta, Departemen Pendidikan Nasional.

Ghufron, Anik, 2011; "Pendekatan Penelitian Dan Pengembangan (R\&D) di Bidang Pendidikan dan Pembelajaran" Jurnal Penelitian Statistik Universitas Padang

Khaeruddin, 2012. “ Belajar Otodidak Adobe Photoshop CS (Menguasai Tanpa Guru) “, Bandung: CV Yrama Widya.

Martono. Heri, 2011. “ Modul Konsep Dasar Pendidikan Anak Usia Dini”. MediaKita, Bandung

Nugraha Warto Adi, 2011; “ Cepat Mahir Corel Draw 11.” ARL: Kuliah Berseri IlmuKomputer.Com.See

Setiawan Sulhan, 2012. “Merancang Aplikasi Flash Secara Optimal “, Yogyakarta: ANDI OFFSET

Siantayani Yulianti, 2011. "Strategi dan Metode Pembelajaran PADU Melalui Bermain yang Bermutu. "“

Wibawanto Wandah, 2014. “ Membuat Game dengan Macromedia Flash “, Yogyakarta : ANDI OFFSET

.http://www.bambangherlandi.info/freedownloads/materi ulangan/SMAN4/Materi\%2 0Ulangan\%20Blok\%20Semester\%20Genap/corell-01.pdf $>$. Diakses pada 8 Januari 2017 .Poetra Abe, 2010; “ Matematika Biner.” ARL: Kuliah Pengantar IlmuKomputer.Com.See

<URL:http://staffsite.gunadarma.ac.id/rodiah/index.php?stateid=download\&id=5372\&par $\mathrm{t}=$ files $->$. Diakses pada 8 Januari 2017

.Prayudi, 2011; “Definisi Computer Game.” ARL: Definisi Computer Game.See <URL: http://cgrg.wordpress.com/2008/03/12/definisi-computer-game/>. Diakses pada 11 Januari 2017

.Schmittberger RW, B.A. J.D, 2009 ; “ Games. " ARL: Encarta.See < URL:http://encarta.msn.com/encyclopedia_761565850/Games.html>. Diakses pada 11 Januari 2017 